\title{
Identification of Sources of Resistance against Wilt (Fusarium oxysporum f. sp. ciceri) in Chickpea Genotypes under Temperate Agro-Climatic Conditions of Kashmir
}

\author{
Shifa Showket ${ }^{1}$, Sabiya Bashir ${ }^{2 *}$, Mohammad Najeeb Mughal ${ }^{1}$, Reyaz-ul-Raouf Mir ${ }^{1}$, \\ F.A. Bhatt ${ }^{1}$ and T.A. Shah ${ }^{1}$
}

${ }^{1}$ Division of Plant Pathology, Faculty of Agriculture, ${ }^{2}$ Dryland Agriculture Research Station, S. K. University of Agricultural Sciences and Technology of Kashmir, Budgam-191132, India

*Corresponding author

\section{A B S T R A C T}

\section{Keywords}

Chickpea, Fusarium wilt,

Genotype screening,

Kashmir, Temperate

agro-climatic conditions

Article Info

Accepted:

04 August 2018

Available Online:

10 September 2018
Thirty five chickpea genotypes in Chickpea International Elite Nursery Winter 2018 (CIEN-W-18), procured from ICARDA were evaluated against wilt caused by Fusarium oxysporum f. sp ciceri during Rabi 2018 under temperate agro-climatic conditions of Kashmir. None of the genotypes were found highly resistant, while only three genotypes viz., FLIP10-355C, FLIP11-40C and FLIP11-45C were Resistant. Seven genotypes viz., FLIP10-332C, FLIP10-343C, FLIP11-125C, FLIP11-163C, FLIP11-175C, FLIP11-190C and FLIP11-231C were moderately resistant while fourteen genotypes viz., FLIP10-318C, FLIP10-333C, FLIP10-364C, FLIP11-05C, FLIP11-06C, FLIP11-09C, FLIP11-11C, FLIP11-22C, FLIP11-32C, FLIP11-58C, FLIP11-134C, FLOP11-151C, FLIP11-193C and FLIP93-93C were moderately susceptible. Eight genotypes viz., FLIP10-337C, FLIP10345C, FLIP11-21C, FLIP11-102C, FLIP11-66C, FLIP11-158C, FLIP82-150C and FLIP88-85C were found susceptible and three genotypes (ILC482, FLIP11-08C and FLIP10-338C) were highly susceptible.

\section{Introduction}

Chickpea (Cicer arietinum L.) is an important pulse crop, which rank third after dry beans (Phaseolus vulgaris L.) and dry peas (Pisum sativum L.) (Dhar and Gurha, 1998). India is largest producer of chickpea in the world contributing 65.49 per cent in production and 65.25 per cent in area. In India chickpea is grown on 81.17 lakh hectare of land, producing 59.01 lakh tonnes with a productivity of $727 \mathrm{~kg} \mathrm{ha}$ (Anonymous, $^{-1}$ 2015). Fusarium oxysporum f. sp. ciceri (Foc, Padwick) is a serious soil borne disease of chickpea (Hossain et al., 2013) and was first reported in Indo-Pak sub-continent by Butler in 1918. It is one of the major constraints in chickpea cultivation throughout the world especially in Indian sub-continent where chickpea is a commonly grown as pulse crop. Nema and Khare (1973) reported yield loss due to wilt upto 61 per cent if the infection 
occurs at seedling stage and 43 per cent if the infection occurs at flowering stage. In India, at National level, the yield loss due to wilt may vary between 5 to 10 per cent (Singh and Dahiya, 1973). However, under congenial weather conditions for disease, it may cause complete (100\%) yield loss (Pande et al., 2010; Kumari and Khanna, 2014).

Though reports on different aspects of the disease are available from India and abroad, very scanty information is available on this disease from Jammu and Kashmir. Although various chemical fungicides are available for management of disease but they incur high cost and cause environmental hazards and deleterious effects on human health. Identification of resistant genotypes is one of the most suitable, cheap and eco-friendly method of management of disease and improving the farmers returns. Keeping in view the importance of disease, socioeconomic status of the crop and inadequate research work carried out, an attempt was made to identify sources of resistance to the disease in the genotypes procured from ICARDA.

\section{Materials and Methods}

Thirty five genotypes, including four Checks viz., ILC482, FLIP-82-150C, FLIP88-85C and FLIP 93-93C, procured from ICARDA were screened against the wilt under natural epiphytotic conditions in Chickpea International Elite Nursery 2018 (CIEN-W18) at FOA, Wadura during Rabi 2017-18. The genotypes were classified into Highly Resistant (HR), Resistant (R), Moderately Resistant (MR), Moderately Susceptible (MS), Susceptible (S) and Highly Susceptible (HS) groups on the basis of their response to disease under natural epiphytotic conditions. All the entries were planted in two replications. Susceptible checks were planted in separate plots. The length of each row was $4 \mathrm{~m}$ and width was $0.45 \mathrm{~m}$. The observation on wilt was recorded as percentage of disease incidence calculated by following formula:

No. of plants exhibiting wilt symptoms Disease incidence $(\%)=$ $\times 100$

Total of total plants observed

A scale $(0-5$ point $)$ was used for categorization of genotypes.

\section{Results and Discussion}

The persual of data (Table 1 and 2) revealed that in Chickpea International Elite Nursery 2018 (CIEN-W-18), none of the genotypes recorded zero disease incidence and no genotype was found Highly Resistant (HR). However, three genotypes viz., FLIP10-355C, FLIP11-40C and FLIP11-45C were Resistant (R) with disease incidence ranging from 4.75 (FLIP10-355C) to 8.75 (FLIP11-45C) per cent and seven genotypes viz., FLIP10-332C, FLIP10-343C,FLIP11-163C, FLIP11-175C, FLIP11-190C and FLIP11-231C were Moderately Resistant (MR) with disease incidence varying from 12.50 in genotype FLIP11-125C to 18.00 per cent in genotype FLIP11-163C and fourteen genotypes viz., FLIP10-318C，FLIP10-333C，FLIP10-364C, FLIP11-05C, FLIP11-06C, FLIP11-09C, FLIP11-11C， FLIP11-22C, FLIP11-32C, FLIP11-58C，FLIP11-134C，FLOP11-151C, FLIP11-193C and FLIP93-93C were designated as moderately susceptible with disease incidence ranging from 21.00 (FIP1122C) to 28.00 (FLIP11-151C) per cent. Eight genotypes FLIP10-337C, FLIP10-345C, FLIP11-21C, FLIP11-102C, FLIP11-66C, FLIP11-158C, FLIP82-150C and FLIP88-85C were susceptible. Among the susceptible genotypes, the lowest disease incidence $(35.00 \%)$ was recorded in genotype FLIP10337C while highest disease incidence $(49.00 \%)$ was recorded in FLIP11-150C genotype. 
Table.1 Reactions of genotypes in Chickpea International Elite Nursery 2018 (CIEN-W-18)

\begin{tabular}{|l|l|l|}
\hline S. No & Genotype & Per cent wilt incidence \\
\hline 01 & FLIP10-355C & 4.75 \\
\hline 02 & FLIP11-40C & 7.75 \\
\hline $\mathbf{0 3}$ & FLIP11-45C & 8.75 \\
\hline 04 & FLI10-332C & 15.75 \\
\hline 05 & FLIP10-343C & 13.00 \\
\hline 06 & FLIP11-125C & 12.50 \\
\hline 07 & FLIP11-163C & 18.00 \\
\hline 08 & FLIP11-175C & 17.75 \\
\hline 09 & FLIP11-190C & 11.00 \\
\hline 10 & FLIP11-231C & 16.25 \\
\hline 11 & FLIP10-318C & 23.50 \\
\hline 12 & FLIP10-333C & 25.00 \\
\hline 13 & FLIP10-364C & 25.00 \\
\hline 14 & FLIP11-05C & 27.75 \\
\hline 15 & FLIP11-06C & 22.25 \\
\hline 16 & FLIP11-09C & 21.00 \\
\hline 17 & FLIP11-11C & 24.75 \\
\hline 18 & FIP11-22C & 21.25 \\
\hline 19 & FLIP11-32C & 24.75 \\
\hline 20 & FLIP11-58C & 24.00 \\
\hline 21 & FLIP11-134C & 22.50 \\
\hline 22 & FLIP11-151C & 28.00 \\
\hline 23 & FLIP11-193C & 21.00 \\
\hline 24 & FLIP93-93C & 23.00 \\
\hline 25 & FLIP10-337C & 35.00 \\
\hline 26 & FLIP10-345C & 38.25 \\
\hline 27 & FLIP11-21C & 40.50 \\
\hline 28 & FLIP11-102C & 42.00 \\
\hline 29 & FLIP11-66C & 43.50 \\
\hline 30 & FLIP11-158C & 45.00 \\
\hline 31 & FLIP11-150C & 49.00 \\
\hline 32 & FLIP88-85C & 43.75 \\
\hline 33 & ILC482 & 53.00 \\
\hline 35 & FLIP11-08C & 55.75 \\
\hline & FLIP10-338C & 52.75 \\
\hline
\end{tabular}


Table.2 Categorization of chickpea genotypes / lines in CIEN-W-18

\begin{tabular}{|c|c|c|c|}
\hline Category & Reaction & $\begin{array}{l}\text { Average wilt incidence } \\
(\%)\end{array}$ & Genotypes/Lines \\
\hline 0 & $\begin{array}{l}\text { Highly resistant } \\
\text { (none) }\end{array}$ & 0 & - \\
\hline 1 & Resistant (3) & $1-10$ & $\begin{array}{l}\text { FLIP10-355C, FLIP11-40C and FLIP11- } \\
45 \mathrm{C}\end{array}$ \\
\hline 2 & $\begin{array}{l}\text { Moderately } \\
\text { resistant (7) }\end{array}$ & $10-20$ & $\begin{array}{l}\text { FLIP10-332C, FLIP10-343C, FLIP11- } \\
\text { 125C, FLIP11-163C, FLIP11-175C, } \\
\text { FLIP11-190C and FLIP11-231C }\end{array}$ \\
\hline 3 & $\begin{array}{l}\text { Moderately } \\
\text { susceptible (14) }\end{array}$ & $20-30$ & $\begin{array}{l}\text { FLIP10-318C, FLIP10-333C, FLIP10- } \\
\text { 364C, FLIP11-05C, FLIP11-06C, } \\
\text { FLIP11-09C, FLIP11-11C, FLIP11-22C, } \\
\text { FLIP11-32C, FLIP11-58C, FLIP11- } \\
\text { 134C, FLOP11-151C, FLIP11-193C and } \\
\text { FLIP93-93C }\end{array}$ \\
\hline 4 & Susceptible (8) & $30-50$ & $\begin{array}{l}\text { FLIP10-337C, FLIP10-345C, FLIP11- } \\
\text { 21C, FLIP11-102C, FLIP11-66C, } \\
\text { FLIP11-158C, FLIP82-150C and } \\
\text { FLIP88-85C }\end{array}$ \\
\hline 5 & $\begin{array}{l}\text { Highly } \\
\text { susceptible (3) }\end{array}$ & $50 \&$ above & ILC482, FLIP11-08C and FLIP10-338C \\
\hline
\end{tabular}

Categorization scale $(0-5)$

$\begin{array}{cl}\text { Grade } & \text { Per cent mortality } \\ 0 & \text { No disease } \\ 1 & 1 \text { to } 10 \\ 2 & 10.1 \text { to } 20 \\ 3 & 20.1 \text { to } 30 \\ 4 & 30.1 \text { to } 50 \\ 5 & 50 \text { and above }\end{array}$

\author{
Disease reactions \\ Highly resistant (HR) \\ Resistant(R) \\ Moderately Resistant (MR) \\ Moderately Susceptible (MS) \\ Susceptible (S) \\ Highly Susceptible (HS)
}

(IIPR, 1999)

Three genotypes were found Highly Susceptible and among them lowest disease incidence $(53.00 \%)$ was recorded in ILC482 followed by FLIP10-338C with disease incidence of 52.75 while genotype FLIP11$08 \mathrm{C}$ recorded the highest disease incidence of 56.75 per cent.

In the present investigation the selection for the resistance was based on the reaction of the genotypes to wilt pathogen, Fusarium oxysporum f. sp. ciceri under natural epiphytotic conditions and the result indicated that three genotypes were Resistant (R) and which could be used as direct introductions or sources of resistance in hybridization programme.

Korde, (2011), Mandhare et al., (2011) and Kumar et al., (2012) gave been screened 
number of chickpea genotypes and identified promising cultivars in India.

\section{References}

Anonymous 2015. Directorate of Economics and Statistics, Department of Agriculture and Cooperation. Agricultural statistics at a glance. $9096 \mathrm{pp}$.

Dhar V. and Gurha S. N. 1998. Integrated management of chickpea diseases. (Rajeev, K., Upadhyay, K. G., Mukerji, B. P., Chamola and Dubey, O. P. (edi.)), APH Pub. Co., New Delhi. (India). 249 pp.

Hossain, M.M., Hossain, N., Sultana, F., Islam, S.M.N., Islam, M.S. Bhuiyan, M.K.A. 2013. Integrated management of Fusarium wilt of chickpea (Cicer arietinum L.) caused by Fusarium oxysporum f. sp. ciceris with microbial antagonist, botanical extract and fungicide. Afr. J. Microbiol. 12(29): 4699-4706.

IIPR 1999. Proceedings of technical programme for Rabi workshop organization by Indian Institute of Pulse Research Kanpur. 13 pp.

Korde M. G. 2011. Studies on Fusarium wilt of chickpea caused by Fusarium oxysporum f. sp. ciceri (Padwik) Synder and Hansan. M. Sc. (Agri.) thesis submitted to VNMKV, Parbhani (India).

Kumar A., Lal H. C. and Akhtar J. 2012. Morphological and pathogenic characterization of Fusarium oxysporum f. sp. ciceri causing wilt of chickpea. Indian Phytopathology. 65 (1): 64-66.
Kumari, S. and Khanna, V. 2014. Effect of antagonistic rhizobacteria coinoculated with Mesorhizobium ciceris on control of Fusarium wilt in chickpea (Cicer arietinum L.). African Journal of Microbiological Research. 8(12): 12551265.

Mandhare V. K., Deshmukh G. P., Patil J. V., Kale A. A. and Chavan U. D. 2011. Morphological, pathogenic and molecular characterization of Fusarium oxysporum f. sp. ciceri isolates from Maharashtra, India. Indonesian Journal of Agricultural Sciences. 12 (2): 47-56.

Nema K. G. and Khare M. N. 1973. A conspectus of wilt of Bengal gram in Madhya pradesh. Symposium on wilt problem and breeding for wilt resistance in Bengal gram, Sept. 1973 at Indian Agricultural. Research Institute, New Delhi, India. 1-4 pp.

Pande, S, Desai, S., Sharma, M. 2010. Impacts of climate change on rainfed crop diseases: Current Status and Future Research Needs. National Symposium on Climate Change and Rainfed Agriculture, Hyderabad. 18(20): 55-59.

Singh K. B. and Dahiya B. S. 1973. Breeding of wilt resistance in chickpea. Symposium on wilt problem and breeding for wilt resistance in Bengal gram. September 1973 at IARI, New Delhi, India, 13-14. pp.

Suryawanshi A V, Mandhare V K, Sanap M M and Jamadagni B M 2003. Reaction of chickpea entries to Fusarium wilt and gram pod borer. J. Maharashtra Agric. Univ. 28 (2): 213-214.

\section{How to cite this article:}

Shifa Showket, Sabiya Bashir, Mohammad Najeeb Mughal, Reyaz-ul-Raouf Mir, F.A. Bhatt and Shah, T.A. 2018. Identification of Sources of Resistance against Wilt (Fusarium oxysporum f. sp. ciceri) in Chickpea Genotypes under Temperate Agro-Climatic Conditions of Kashmir. Int.J.Curr.Microbiol.App.Sci. 7(09): 195-199. doi: https://doi.org/10.20546/ijcmas.2018.709.025 